\title{
The impact of hearing loss on language performance in older adults with different stages of cognitive function
}

This article was published in the following Dove Press journal:

Clinical Interventions in Aging

9 April 2015

Number of times this article has been viewed

\author{
Leire Lodeiro-Fernández \\ Laura Lorenzo-López \\ Ana Maseda \\ Laura Núñez-Naveira \\ José Luis Rodríguez-Villamil \\ José Carlos Millán-Calenti \\ Gerontology Research Group, \\ Department of Medicine, Faculty \\ of Health Sciences, University of \\ A Coruña, Campus of A Coruña, \\ A Coruña, Spain
}

Correspondence: José Carlos Millán-

Calenti

Gerontology Research Group,

Department of Medicine, Faculty

of Health Sciences, University of A

Coruña, Campus de A Coruña, I507I

A Coruña, Spain

Tel +34 98I I67000 ext 5865

Fax $+34981 \quad 67 \quad 120$

Email jcmillan@udc.es
Purpose: The possible relationship between audiometric hearing thresholds and cognitive performance on language tests was analyzed in a cross-sectional cohort of older adults aged $\geq 65$ years $(\mathrm{N}=98)$ with different degrees of cognitive impairment.

Materials and methods: Participants were distributed into two groups according to Reisberg's Global Deterioration Scale (GDS): a normal/predementia group (GDS scores 1-3) and a moderate/moderately severe dementia group (GDS scores 4 and 5). Hearing loss (pure-tone audiometry) and receptive and production-based language function (Verbal Fluency Test, Boston Naming Test, and Token Test) were assessed.

Results: Results showed that the dementia group achieved significantly lower scores than the predementia group in all language tests. A moderate negative correlation between hearing loss and verbal comprehension $(r=-0.298 ; P<0.003)$ was observed in the predementia group $(r=-0.363 ; P<0.007)$. However, no significant relationship between hearing loss and verbal fluency and naming scores was observed, regardless of cognitive impairment.

Conclusion: In the predementia group, reduced hearing level partially explains comprehension performance but not language production. In the dementia group, hearing loss cannot be considered as an explanatory factor of poor receptive and production-based language performance. These results are suggestive of cognitive rather than simply auditory problems to explain the language impairment in the elderly.

Keywords: auditory impairment, verbal function, aging, cognition

\section{Introduction}

The prevalence of hearing loss in older adults is very high, with up to $30 \%$ of men and $20 \%$ of women by the age of 70 years and $55 \%$ of men and $45 \%$ of women over 80 years presenting hearing loss of at least 30 decibels of hearing level (dB HL). ${ }^{1}$ This age-related hearing loss first affects higher tones. ${ }^{2}$ When mild, it leads to problems following conversations in noisy and reverberant listening situations, progressing to difficulties following any conversation as it becomes more severe, due to problems with the discrimination of words and even voice identification. ${ }^{2,3}$

Sensory deficits, including hearing loss, are considered one of the major geriatric syndromes because of the important negative impact they generate on individual emotional, physical, and social levels. ${ }^{4-6}$ In fact, hearing loss has been associated with depressive symptoms, ${ }^{7}$ impaired communication and social relationships, ${ }^{8}$ and increased difficulty in activities of daily living. ${ }^{9}$

Despite the negative functional, psychological, and social consequences of hearing loss, ${ }^{10,11}$ its effects on intellectual/cognitive functioning is not completely clear, although it has been previously discussed. ${ }^{12-16}$ 
Early studies demonstrated the association between hearing impairment and dementia in elderly populations, ${ }^{14,16}$ being that hearing loss significantly and independently correlated with the severity of the cognitive dysfunction. ${ }^{16-18}$ In a recent neuroimaging study, peripheral hearing loss was also associated with accelerated brain atrophy in whole brain and regional volumes concentrated in the right temporal lobe. ${ }^{19}$ It is not completely clear, however, whether hearing loss has a causative role in cognitive decline, is a modifiable risk factor for the development of dementia, or if both the hearing loss and the cognitive decline are parts of a common, general age-related degeneration. ${ }^{12}$

Since the degree of hearing loss appears to be linked to cognitive decline and risk of developing dementia, ${ }^{16-18}$ and might be potentially treatable and modifiable by using hearing aids, the study of the possible relationship between hearing loss and cognitive impairment is of clinical and public health relevance. Taking into account that language is the cognitive function most linked to hearing, we set out to investigate impairment of hearing as an explanatory factor of language impairment in older adults. This work presents a study of the relationship between hearing and language function in older adults with a range of cognitive impairments using standardized audiometric testing protocol and neurocognitive tests, in order to further explore the mechanisms linking hearing loss with cognitive impairment and dementia. To test the language function, both expression/production and oral comprehension were tested, since these capacities have been shown to be good indicators of cognitive impairment ${ }^{20}$ and to be affected in dementia patients. ${ }^{21}$ Naming and fluency impairment has been previously related to abnormalities in temporal and frontal brain regions ${ }^{21}$ and deficits in oral comprehension have been correlated with predominantly left frontal abnormalities. ${ }^{22}$ Specifically, to assess language expression/production, the Verbal Fluency Test (VFT) ${ }^{23,24}$ and the short form of the Boston Naming Test (BNT) ${ }^{25}$ were administered, and, to assess oral comprehension, a key feature for communication, the Token Test (TT) ${ }^{26}$ was used.

\section{Materials and methods Participants}

A comparative, descriptive, cross-sectional study was carried out on a sample of 103 subjects aged $\geq 65$ years from a gerontological complex in A Coruña, Spain. Approval was obtained from the Ethics Committee of the University of A Coruña and the study was in conformity with the principles embodied in the Declaration of Helsinki. All participants were previously informed and gave their consent to participate in the study, either directly or through their legal representatives. The sample was divided into two groups according to Reisberg's Global Deterioration Scale (GDS). ${ }^{27}$ This scale, which has been proven to be reliable and valid for staging dementia in different settings, ${ }^{28}$ describes seven stages of cognitive function from 1 (no subjective complaints of memory deficit) to 7 (very severe cognitive impairment). Thus, using this scoring system, we established a normal/predementia group (GDS scores between 1 and 3; $1=$ no cognitive decline, $2=$ very mild cognitive decline, $3=$ mild cognitive decline) and a moderate/moderately severe dementia group (GDS scores 4 and 5; 4= moderate cognitive decline, $5=$ moderately severe cognitive decline). The exclusion criteria were: subjects with language disorders generated by a non-dementia-related disorder etiology, such as stroke (aphasia); subjects with hearing aids in order to avoid those variables that might interfere with the natural effect of hearing loss over language performance; and subjects with characteristics incompatible with the administration of the selected screening tests and/or assessment: alteration of visual perception of images and colors, motor ability limitation in the upper extremities, or those classified as GDS level 6 or 7 (severe and very severe cognitive impairment).

\section{Language and hearing assessments}

The specific instruments selected to assess language function were the VFT, ${ }^{23,24}$ to specifically assess verbal fluency; the short form of the BNT, ${ }^{25}$ to assess confrontation-naming performance; and the $\mathrm{TT},{ }^{26}$ to assess verbal comprehension. The instructions were given in auditory mode. Regarding the VFT, participants were asked to name as many things as possible in the "animal category" within 60 seconds. The total score corresponds to the number of correct and non-repeated animals named (lower scores indicating greater cognitive impairment; the cutoff for impairment has been established as $<10$ points). ${ }^{29}$ Regarding the BNT, participants were asked to name the presented pictures (a set of line drawings of 15 common objects), and they were allowed approximately 20 seconds in which to spontaneously name each drawing. If the correct word was not produced in that time, a phonemic cue was given and an additional period of 20 seconds was allowed for a response. The TT requires 20 plastic tokens that vary in color, size, and shape and 62 verbal commands. The participants had to give a gestural response (pointing to or moving tokens) in response to each verbal command. The commands progressively become more difficult according to length of the command, syntactic complexity, and working memory demand. The score was calculated by 
assigning one point for each item answered correctly. The cutoff for impairment is set to 49 points. The tests were presented in the absence of reverberation and background noise.

Since, most commonly, age-related hearing loss is caused by sensorineural factors, ${ }^{30}$ only pure-tone average (PTA) was measured in the present paper, excluding conductive hearing loss measures. Auditory acuity was measured in a Sibelmed S-40 soundproof booth (AC-50B audiometer), via pure-tone audiometry for $0.5,1,2$, and $4 \mathrm{kHz}$ frequency tones presented to the right and left ear. The grades of hearing impairment were classified based on the World Health Organization (WHO) ${ }^{31}$ definitions, which take the hearing threshold level as the average of hearing thresholds for the four frequencies $(0.5,1,2$, and $4 \mathrm{kHz})$ in the better-hearing ear (PTA): a hearing loss of 26-40 dB HL corresponds to a slight impairment; a loss of 41-60 dB HL indicates a moderate impairment; a loss of 61-80 dB HL indicates a severe impairment; and a loss of more than $80 \mathrm{~dB}$ HL suggests a profound impairment.

\section{Statistical analysis}

All statistical analyses were performed using the PASW Statistics 18 statistical package version 18.0.0 (SPSS Inc., Chicago, IL, USA). ${ }^{32}$ The level of significance was defined as $P<0.05$. Sample characteristics were analyzed using descriptive statistics (mean \pm standard deviation) and frequency distributions. Language performance and hearing scores were compared between the predementia and dementia groups by means of Student's $t$-test for independent samples. In order to investigate the relationship between hearing loss and language scores, Pearson's correlation coefficients $(r)$ were computed.

\section{Results}

\section{Sample characteristics}

In total, 103 subjects met the inclusion criteria but, during the audiometric testing, five subjects (GDS5) were excluded from the study for being unable to comprehend and perform the tests. The final sample consisted of 98 subjects, with $54(55.1 \%)$ meeting the criteria defined for the normal/ predementia group, and $44(44.9 \%)$ for the moderate/ moderately severe dementia group. Five subjects in the predementia group $(9.3 \%)$ were classified as being without cognitive impairment (GDS1), 23 (42.6\%) had very mild cognitive impairment (GDS2), and the remaining 26 (48.1\%) suffered from mild cognitive impairment (GDS3). In the dementia group, 28 subjects (63.6\%) exhibited moderate cognitive impairment (GDS4) and 16 (36.4\%) exhibited moderately severe cognitive impairment (GDS5).
The sociodemographic characteristics of the sample (age, sex, and level of education) are shown in Table 1 as a function of the group (predementia, dementia). There was no statistically significant difference between the two groups in mean age $(t(96)=-1.323, P=0.189)$.

Audiometry results revealed that five participants (5.1\%) presented normal hearing (PTA $<26 \mathrm{~dB}$ HL), 31 (31.6\%) presented mild hearing loss (PTA 26-40 dB HL), 56 (57.2\%) showed moderate loss (PTA 41-60 dB HL), and six (6.1\%) presented severe loss (PTA 61-80 dB HL). No subject with profound hearing loss was found. The mean pure-tone audiometry threshold at $0.5,1,2$, and $4 \mathrm{kHz}$ of the better-hearing ear was $42.5 \pm 11.0 \mathrm{~dB}$ HL (ranging from 15.0 to $68.7 \mathrm{~dB} \mathrm{HL}$ ) for the predementia group and $44.9 \pm 10.4 \mathrm{~dB} \mathrm{HL}$ (ranging from 23.7 to $62.5 \mathrm{~dB} \mathrm{HL}$ ) for the dementia group, showing that both groups presented moderate hearing impairments based on WHO definitions, in which a PTA exceeding $25 \mathrm{~dB}$ HL is considered the level at which hearing loss begins to impair daily communication. As effects of between-group comparisons, Figure 1 displays mean auditory thresholds (dB HL) in the better-hearing ear for the predementia and dementia groups plotted as a function of tone frequency.

\section{Hearing loss and language performance relationship}

Table 2 shows audiometric and language tests scores (VFT, BNT, TT) as a function of the degree of cognitive impairment specified by the GDS level. Student's $t$-test revealed statistically significant differences between the predementia and dementia groups for all language tests (all $P$-values $<0.0001$ ) but not for audiometric scores $(P=0.274)$.

The possible relationship between hearing loss and language performance was explored by computing the

Table I Demographic data

\begin{tabular}{|c|c|c|}
\hline Variable & $\begin{array}{l}\text { Predementia } \\
(n=54)\end{array}$ & $\begin{array}{l}\text { Dementia } \\
(n=44)\end{array}$ \\
\hline Mean age $\pm S D$ (range), years & $82.4 \pm 6.6(65-94)$ & $84.1 \pm 5.7(66-94)$ \\
\hline \multicolumn{3}{|l|}{ Sex } \\
\hline Females, n (\%) & $37(68.5)$ & $37(84.1)$ \\
\hline Males, n (\%) & $17(3 \mid .5)$ & $7(15.9)$ \\
\hline GDS score, mean \pm SD & $2.4 \pm 0.6$ & $4.4 \pm 0.5$ \\
\hline \multicolumn{3}{|l|}{ Education } \\
\hline Illiterate, n (\%) & $2(3.6)$ & I (2.3) \\
\hline $\begin{array}{l}\text { No formal education, } \\
\text { but can read, } \mathrm{n}(\%)\end{array}$ & $9(16.7)$ & $17(38.6)$ \\
\hline Primary school, n (\%) & $28(51.9)$ & $20(45.5)$ \\
\hline Secondary school, n (\%) & $8(14.8)$ & $3(6.8)$ \\
\hline University, n (\%) & $7(13.0)$ & $3(6.8)$ \\
\hline
\end{tabular}

Abbreviations: SD, standard deviation; GDS, Global Deterioration Scale. 


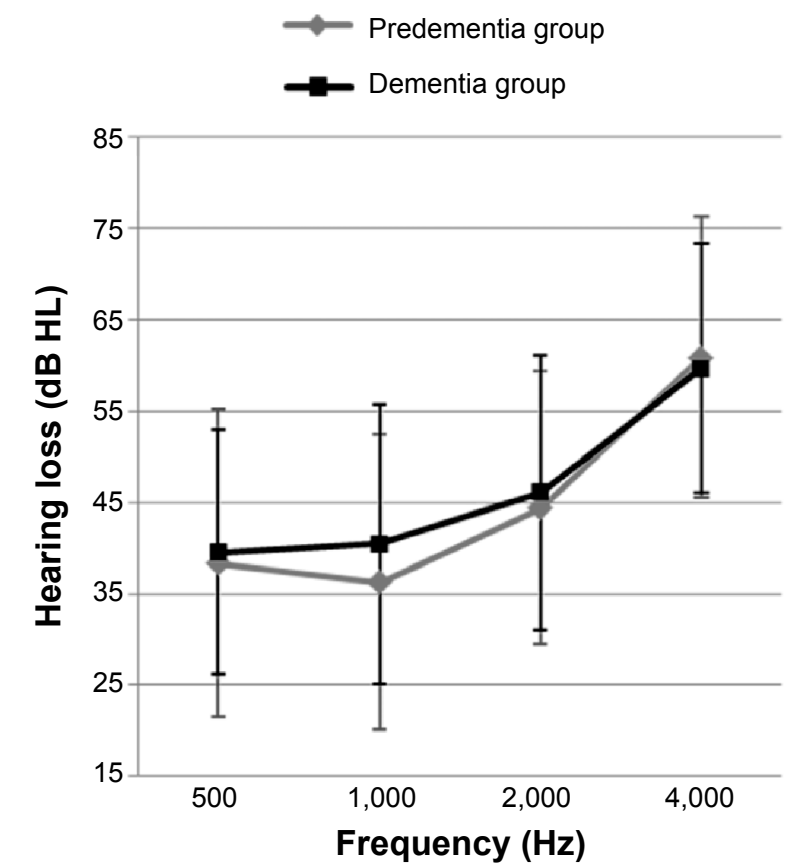

Figure I Mean hearing loss ( $\mathrm{dB} H \mathrm{HL})$ with standard deviations as error bars in the better-hearing ear for the predementia and dementia groups plotted as a function of tone frequency.

Abbreviation: $\mathrm{dB} \mathrm{HL}$, decibels of hearing level.

Pearson correlation. The correlation coefficients and their corresponding $P$-values are shown in Table 3 as a function of the degree of cognitive impairment.

As can be seen in Table 3, no statistical correlation between hearing loss and language impairment, as measured by the VFT or BNT, was found. Nevertheless, a statistically significant correlation between hearing loss and language comprehension (TT) was observed in the predementia group $(r=-0.363, P<0.007)$.

A scatterplot describing the strength and direction of this association between the verbal comprehension performance (TT scores) and hearing loss in the predementia group is

Table 2 Audiometric and language scores as a function of Global Deterioration Scale group

\begin{tabular}{lllll}
\hline & $\begin{array}{l}\text { Predementia } \\
(\mathbf{n}=\mathbf{5 4})\end{array}$ & $\begin{array}{l}\text { Dementia } \\
(\mathbf{n}=\mathbf{4 4})\end{array}$ & $\boldsymbol{t}(\mathbf{d f})$ & P-value \\
\hline PTA & $42.5 \pm 11.0$ & $44.9 \pm 10.4$ & $-1.100(96)$ & 0.274 \\
VFT & $9.5 \pm 3.8$ & $4.0 \pm 2.1$ & $8.509(96)$ & $0.000 * *$ \\
BNT & $7.7 \pm 2.7$ & $4.8 \pm 2.0$ & $5.780(96)$ & $0.000 * *$ \\
TT & $48.1 \pm 9.5$ & $31.8 \pm 10.5$ & $8.069(96)$ & $0.000 * *$
\end{tabular}

Notes: PTA was of hearing thresholds at $0.5, \mathrm{I}, 2$, and $4 \mathrm{kHz}$ in the better-hearing ear (decibels of hearing level). The results are expressed as the mean values \pm the standard deviation. $* * P<0.001$.

Abbreviations: PTA, pure-tone average; VFT, Verbal Fluency Test; BNT, Boston Naming Test; TT, Token Test; $d f$, degrees of freedom. depicted in Figure 2. As shown in the figure, data lie on a straight line with a negative slope, indicating that, as hearing loss increases, the verbal comprehension performance decreases in this group.

The moderate association $(r=-0.363)$ implies that $13.2 \%$ $\left(-0.363^{2}\right)$ of the variation in TT scores is explained by hearing loss (Cohen's $d$ effect size $=0.78$ ).

\section{Discussion}

In the present paper, outcomes in measures of language comprehension and production/expression were investigated in older adults with a range of hearing abilities who were divided into predementia and dementia groups, in order to estimate the extent to which language impairment is related to hearing loss and whether this may provide insight into the mechanism by which hearing is related to cognition in general.

\section{Language and hearing assessments}

Regarding participants' performance on verbal cognitive tests, the dementia group generated a lower number of evoked words in the semantic fluency task, made more errors in naming pictures of objects, and showed inferior verbal comprehension performance compared to the predementia group. In accordance with these results, we recently observed an inverse relationship between performance on language tests and cognitive impairment level with a more pronounced effect on fluency and comprehension tests. ${ }^{20}$ It has also been shown that verbal comprehension undergoes some age-related impairment manifested by difficulties in lexical access, syntactic processing, and discourse organization, ${ }^{33}$ which is aggravated in cognitively declined adults.

Auditory acuity results showed mild-to-moderate hearing impairments according to the WHO standard ${ }^{31}$ regardless of the degree of cognitive impairment. In fact, our study did not find a significantly higher average level of hearing loss in the dementia group, which has been found in other studies, ${ }^{16,17}$ possibly because our sample was smaller and there may have been other characteristics that differed from these studies such as the screening criteria used to determine the severity of the cognitive impairment, or audiometric assessments. It is important to note that we only used PTA to assess hearing sensitivity in the present study, and that the possible hearing loss caused by external and middle-ear diseases or by auditory neuropathy cannot be determined. 
Table 3 Correlation between hearing loss and language scores as a function of Global Deterioration Scale group

\begin{tabular}{|c|c|c|c|c|c|c|}
\hline & \multicolumn{6}{|c|}{ Hearing loss } \\
\hline & \multicolumn{2}{|c|}{ Predementia } & \multicolumn{2}{|c|}{ Dementia } & \multicolumn{2}{|c|}{ Total $(\mathbf{N}=98)$} \\
\hline & $r$ & $P$-value & $r$ & $P$-value & $r$ & $P$-value \\
\hline \multicolumn{7}{|c|}{ Language scores } \\
\hline VFT & -0.070 & 0.614 & -0.317 & 0.056 & -0.104 & 0.310 \\
\hline BNT & -0.055 & 0.693 & -0.146 & 0.345 & -0.129 & 0.206 \\
\hline $\mathrm{TT}$ & -0.363 & $0.007 * *$ & -0.227 & 0.139 & -0.298 & $0.003^{*}$ \\
\hline
\end{tabular}

Notes: Pearson's correlation coefficient $(r)$ between hearing loss and language performance. $* P<0.05 ; * * P<0.00$ I.

Abbreviations: VFT, Verbal Fluency Test; BNT, Boston Naming Test; TT, Token Test.

\section{Hearing loss and language impairment relationship}

Hearing loss and language comprehension

It has been widely suggested that sensory declines may adversely affect cognitive functions dependent on sensory input. ${ }^{34}$ In the present study, greater hearing loss was significantly associated with lower scores on measures of verbal comprehension (TT scores) in the normal/predementia group. It is important to note, at this point, that since the predementia and dementia groups were age-homogeneous, presented a similar degree of hearing loss, and were assessed under similar conditions, the differences between them are unlikely to be confounded by these factors. Possible confounding of age and testing conditions in the relationship between hearing loss and decreased performance in the verbal comprehension task within these groups is therefore reduced.

The finding of a moderate negative association between hearing loss and verbal comprehension is consistent with

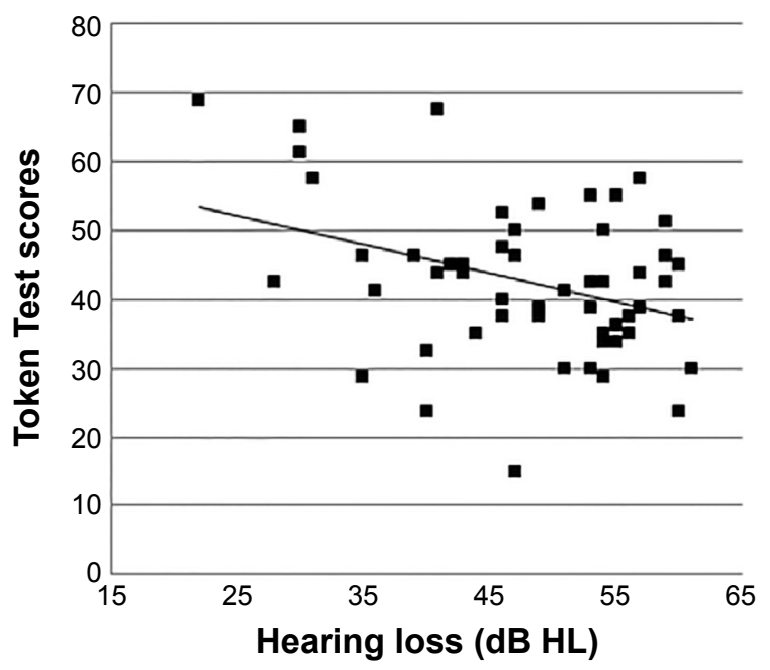

Figure 2 Scatterplot showing a moderate negative linear relationship between Token Test scores and hearing loss in the predementia group.

Abbreviation: $\mathrm{dB} H \mathrm{HL}$, decibels of hearing level. prior research revealing significant associations between hearing loss and poorer cognitive function on both verbal ${ }^{13,16,35,36}$ and nonverbal cognitive tests..$^{35}$ This finding suggests that a loss in peripheral hearing sensitivity may partially explain verbal comprehension difficulties in the predementia group, along with a contribution from other cognitive factors, such as working memory and attentional/ inhibitory resources ${ }^{37,38}$ and general information processing speed. ${ }^{39}$ The lack of significant association between hearing loss and verbal comprehension in the group with moderate/ moderately severe dementia suggests that when cognitive impairment increases, the importance of hearing loss on language function becomes smaller.

Understanding syntactically complex sentences such as those in the TT implies demands of cognitive resources, and the greater perceptual effort due to hearing loss appears to affect this, with subsequent diminished performance. ${ }^{40}$ A number of different groups have shown that listening comprehension problems in the elderly are due to hearing loss and cognition to varying degrees depending on the situation. ${ }^{3,41,42}$ Indeed, older adults with normal cognition can use contextual information and their own knowledge to compensate for their deficiencies in auditory perception. ${ }^{15}$

Since only cross-sectional data were analyzed, it cannot be definitely concluded that hearing loss is an inducer of comprehension deterioration in the predementia group or whether there is a shared cause of the two. Based on previous studies and in our own results, it can be concluded that, at least when mild-to-moderate hearing loss is present, there might be some other causes of cognitive origin, such as a slowing down in processing rates or deficits in working memory, or selective attention, in addition to hearing impairment to explain the language difficulties in older adults. Indeed, hearing loss may interact with other risk factors of cognitive impairment.

It is important to note that the present study relied on pure-tone audiometry, which has been considered as a 
measure mainly reflecting peripheral hearing loss without higher auditory cortical processing. ${ }^{43}$ However, central auditory dysfunction has been shown to be evident in subjects with even mild hearing loss, ${ }^{44}$ and it has been recently demonstrated that hearing loss also affects neural systems supporting speech comprehension in older adults, ${ }^{45}$ with even moderate declines in peripheral auditory acuity leading to a systematic downregulation of neural activity (primary auditory cortex, thalamus, and brainstem). Based on these results, problems in central auditory processing may be a mediator in the observed language impairment.

\section{Hearing loss and language production/expression}

No significant relationships between hearing loss and impaired verbal fluency and naming ability were found in the present study, regardless of the degree of cognitive impairment. It is important to take into account that these cognitive tests do not rely heavily on presentation of auditory information, and are mainly language production measures. Thus, the modality and the type of test material may partially explain the present findings. In fact, the comprehension of language is crucial to correctly perform the TT, in which verbal instructions that become progressively more difficult are given, and that imply the understanding of the semantic significance of each word.

In regards to verbal fluency, in a previous study exploring verbal retrieval/fluency in older adults with acquired sensorioneural hearing impairment, no significant association between hearing loss and category fluency performance was found, but this association was present in letter fluency, ${ }^{46}$ suggesting a less flexible phonology in subjects with hearing loss. This kind of result suggests that letter fluency is more sensitive to acquired hearing loss than category fluency as employed in the present study.

It has been shown that the association between hearing loss and lower performance on cognitive tests is weaker when nonverbal, visually presented tests of memory and attention are administered. ${ }^{47}$ In this context, it has been suggested that the cognitive ability of older people with hearing loss can be underestimated if they are assessed through verbal memory tests; ${ }^{48}$ similarly, some cases of hearing loss can be mistakenly diagnosed as dementia. ${ }^{18}$

Three main classical and possibly interrelated hypotheses have been offered to explain the relationship between sensory and cognitive functioning in the elderly: the sensory deprivation hypothesis, the aging-induced cognitive load hypothesis of sensory performance, and the common cause hypothesis. ${ }^{13}$ The sensory deprivation hypothesis states that sensory degradation of sensory input interferes with cognitive efficacy. The cognitive load explanation suggests that, as hearing loss occurs, greater cognitive resources are dedicated to auditory perceptual processing to the detriment of other cognitive process. Further, the common cause hypothesis explains the age-related differences in sensory and cognitive function as the outcome of degenerative processes in neural structures. Recently, a new explanation has been offered to account for this association attending to decreased social engagement. ${ }^{17}$ In fact, presenting hearing loss tends to isolate people from others, and being socially isolated has been considered as a risk factor for cognitive decline and dementia.

In the present paper, the relationship between hearing loss and cognitive functioning was different across the types of language tests employed and between the predementia and dementia groups, thus the results do not support the common cause hypothesis. In fact, greater hearing loss was significantly associated with lower scores on measures of verbal comprehension (and not on the productive measures such as fluency and naming tasks), and only in the predementia group. Based on these findings, it could be expected that the correction of hearing impairment by the use of hearing aids would not significantly ameliorate the cognitive language dysfunction observed in the dementia group, but possibly would improve social, emotional, and communicative functions and general quality of life. ${ }^{12}$ It is important to note at this point that, in the present study, the groups were dichotomized based on the $\mathrm{GDS}^{27}$ (predementia vs dementia), and it would also be interesting to explore the impact of hearing loss on language performance separately in groups with no cognitive impairment, mild cognitive impairment, and dementia.

The cognitive load hypothesis is difficult to probe in the present study since both groups showed similar mildto-moderate hearing loss, and thus similar perception difficulties, besides significant differences in language performance. Finally, the mediation of social isolation factors cannot be discarded since social networks were not explored in our study. Thus, it cannot be completely discarded that auditory function plays an indirect role through its effects on social relations.

\section{Conclusion}

Our results suggest that, in the group with less cognitive impairment (normal/predementia group), hearing loss has a moderate association with language comprehension; however, when cognitive impairment increases (moderate/moderately severe dementia group), the importance of cognitive factors becomes greater. Thus, while hearing loss explains some comprehension problems in older adults, it cannot explain other 
language problems. Other causes are likely to be of generalized cognitive origin. This agrees with other studies on the relative contribution of hearing and distributed cognitive functions such as processing speed, working memory, and selective attention to language abilities in older adults. As hearing loss was not related to productive language difficulties, the results do not support the hypothesis that mild-tomoderate hearing loss directly contributes to generalized cognitive impairment. Overall, our results are suggestive of cognitive rather than simply auditory problems to explain the language impairment in the elderly. These findings contribute to further understanding of the relation between hearing impairment and cognition and may have important implications on the screening and diagnosis of cognitive decline in older people with a hearing impairment. However, future studies including a wider range of hearing loss, central auditory processing tests, and neuropsychological instruments exploring attention and executive processes would be necessary to establish robust conclusions on this topic.

\section{Acknowledgment}

The authors sincerely thank the Gerontological Complex "La Milagrosa" (A Coruña) for providing access to their elderly residents.

\section{Author contributions}

All authors contributed toward data analysis, drafting and revising the paper and agree to be accountable for all aspects of the work.

\section{Disclosure}

The authors report no conflicts of interest in this work.

\section{References}

1. Roth TN, Hanebuth D, Probst R. Prevalence of age-related hearing loss in Europe: a review. Eur Arch Otorhinolaryngol. 2011;268:1101-1107.

2. Liu XZ, Yan D. Ageing and hearing loss. J Pathol. 2007;211:188-197.

3. van Rooij JC, Plomp R. Auditive and cognitive factors in speech perception by elderly listeners. II: Multivariate analyses. J Acoust Soc Am. 1990;88:2611-2624.

4. Gispen FE, Chen DS, Genther DJ, Lin FR. Association between hearing impairment and lower levels of physical activity in older adults. $J \mathrm{Am}$ Geriatr Soc. 2014;62:1427-1433.

5. Helzner EP, Patel AS, Pratt S, et al. Hearing sensitivity in older adults: associations with cardiovascular risk factors in the health, aging and body composition study. J Am Geriatr Soc. 2011;59:972-979.

6. Millán-Calenti JC, editor. Trastornos de los órganos de los sentidos [Disorders of the sense organs]. In: Principios de Geriatria y Gerontologia [Principles of Geriatric Medicine and Gerontology]. Madrid: McGraw-Hill Interamericana; 2006:589-590. Spanish.

7. Millán-Calenti JC, Maseda A, Rochette S, García-Monasterio I. [Relationship between sensory hearing loss and depression in elderly people: a literature review]. Rev Esp Geriatr Gerontol. 2011;46:30-35. Spanish.
8. Crews JE, Campbell VA. Vision impairment and hearing loss among community-dwelling older Americans: implications for health and functioning. Am J Public Health. 2004;94:823-829.

9. Yamada M, Nishiwaki Y, Michikawa T, Takebayashi T. Impact of hearing difficulty on dependence in activities of daily living (ADL) and mortality: a 3-year cohort study of community-dwelling Japanese older adults. Arch Gerontol Geriatr. 2011;52:245-249.

10. Ciorba A, Bianchini C, Pelucchi S, Pastore A. The impact of hearing loss on the quality of life of elderly adults. Clin Interv Aging. 2012;7:159-163.

11. Salgado Alba A, Guillén Llera F, Ruipérez I. Manual de Geriatría [Handbook of Geriatrics]. 3rd ed. Barcelona: Masson; 2002. Spanish.

12. Arlinger $\mathrm{S}$. Negative consequences of uncorrected hearing loss a review. Int J Audiol. 2003;42 Suppl 2:2S17-2S20.

13. Baltes PB, Lindenberger U. Emergence of a powerful connection between sensory and cognitive functions across the adult life span: a new window to the study of cognitive aging? Psychol Aging. 1997;12: $12-21$.

14. Peters CA, Potter JF, Scholer SG. Hearing impairment as a predictor of cognitive decline in dementia. J Am Geriatr Soc. 1988;36:981-986.

15. Pichora-Fuller MK. Cognitive aging and auditory information processing. Int J Audiol. 2003;42 Suppl 2:2S26-2S32.

16. Uhlmann RF, Larson EB, Rees TS, Koepsell TD, Duckert LG. Relationship of hearing impairment to dementia and cognitive dysfunction in older adults. JAMA. 1989;261:1916-1919.

17. Lin FR, Yaffe K, Xia J, et al; Health ABC Study Group. Hearing loss and cognitive decline among older adults. JAMA Intern Med. 2013;173: 293-299.

18. Lin FR, Metter EJ, O’Brien RJ, Resnick SM, Zonderman AB, Ferrucci L. Hearing loss and incident dementia. Arch Neurol. 2011;68:214-220.

19. Lin FR, Ferrucci L, An Y, et al. Association of hearing impairment with brain volume changes in older adults. Neuroimage. 2014;90:84-92.

20. Maseda A, Lodeiro-Fernández L, Lorenzo-López L, Núñez-Naveira L, Balo A, Millán-Calenti JC. Verbal fluency, naming and verbal comprehension: three aspects of language as predictors of cognitive impairment. Aging Ment Health. 2014;18(8):1037-1045.

21. Melrose RJ, Campa OM, Harwood DG, Osato S, Mandelkern MA, Sultzer DL. The neural correlates of naming and fluency deficits in Alzheimer's disease: an FDG-PET study. Int $J$ Geriatr Psychiatry. 2009;24(8):885-893.

22. Frings L, Dressel K, Abel S, et al. Longitudinal cerebral diffusion changes reflect progressive decline of language and cognition. Psychiatry Res. 2013;214(3):395-401.

23. Lezak MD. A compendium of tests and assessment techniques. In: Lezak MD, Howieson DB, Loring DW, editors. Neuropsychological Assessment. 4th ed. New York: Oxford University Press; 2004:337-785.

24. Spreen O, Strauss E. A Compendium of Neuropsychological Tests: Administration, Norms, and Commentary. 2nd ed. New York: Oxford University Press; 1998.

25. Kaplan E, Goodglass H, Weintraub S. Test de Vocabulario de Boston [Boston Naming Test]. In: Goodglass H, Kaplan E, editors. Evaluación de la afasia y de trastornos relacionados [Boston diagnostic aphasia examination set]. Madrid: Médica Panamericana; 2005:A3.1-A3.9. Spanish.

26. De Renzi E, Vignolo LA. The token test: a sensitive test to detect receptive disturbances in aphasics. Brain. 1962;85:665-678.

27. Reisberg B, Ferris SH, de Leon MJ, Crook T. The Global Deterioration Scale for assessment of primary degenerative dementia. Am J Psychiatry. 1982;139:1136-1139.

28. Rikkert MG, Tona KD, Janssen L, et al. Validity, reliability, and feasibility of clinical staging scales in dementia: a systematic review. Am J Alzheimers Dis Other Demen. 2011;26:357-365.

29. Carnero-Pardo C, Lendínez-González A. Utilidad del test de fluencia verbal semántica en el diagnóstico de demencia [The utility of the semantic verbal fluency test in diagnosis of dementia]. Rev Neurol. 1999; 29:709-714.

30. Mao Z, Zhao L, Pu L, Wang M, Zhang Q, He DZ. How well can centenarians hear? PLoS One. 2013;8(6):e65565. 
31. World Health Organization. Deafness and Hearing Impairment Survey. Report of the Consultative Meeting of Principal Investigators. New Delhi: World Health Organization Regional Office for South-East Asia; 2001. Available from: http://apps.searo.who.int/PDS_DOCS/ B1473.pdf. Accessed January 8, 2014.

32. PASW Statistics 18 Core System User's Guide. Chicago, IL: SPSS Inc.; 2009. Available from: http://data.uni-klu.ac.at/zid_software/ Dokumentationen/SPSS/ver_18/EN/SPSS_Statistics_18_Core_ System_User's_Guide.pdf. Accessed February 11, 2014.

33. Juncos Rabadán O, editor. Involución y deterioro en el desarrollo del lenguaje [Involution and impairment in the language development]. In: Lenguaje y Envejecimiento: Bases Para la Intervención [Language and Aging: Basis for the Intervention]. Barcelona: Masson; 1998:1-20. Spanish.

34. Behrman S, Chouliaras L, Ebmeier KP. Considering the senses in the diagnosis and management of dementia. Maturitas. 2014;77:305-310.

35. Lin FR, Ferrucci L, Metter EJ, An Y, Zonderman AB, Resnick SM. Hearing loss and cognition in the Baltimore Longitudinal Study of Aging. Neuropsychology. 2011;25:763-770.

36. Tay T, Wang JJ, Kifley A, Lindley R, Newall P, Mitchell P. Sensory and cognitive association in older persons: findings from an older Australian population. Gerontology. 2006;52:386-394.

37. Salthouse TA. Aging associations: influence of speed on adult age differences in associative learning. J Exp Psychol Learn Mem Cogn. 1994; 20:1486-1503.

38. Sommers MS, Hale S, Myerson J, Rose N, Tye-Murray N, Spehar B. Listening comprehension across the adult lifespan. Ear Hear. 2011;32: 775-781.

39. Salthouse TA. The processing-speed theory of adult age differences in cognition. Psychol Rev. 1996;103:403-428.
40. Stewart R, Wingfield A. Hearing loss and cognitive effort in older adults' report accuracy for verbal materials. J Am Acad Audiol. 2009; 20:147-154.

41. Humes LE. The contributions of audibility and cognitive factors to the benefit provided by amplified speech to older adults. J Am Acad Audiol. 2007; 18:590-603.

42. Schneider BA, Daneman M, Murphy DR. Speech comprehension difficulties in older adults: cognitive slowing or age-related changes in hearing? Psychol Aging. 2005;20:261-271.

43. Pickles JO. An Introduction to the Physiology of Hearing. Bingley: Emerald Group Publishing; 2008.

44. Gates GA, Karzon RK, Garcia P, et al. Auditory dysfunction in aging and senile dementia of the Alzheimer's type. Arch Neurol. 1995;52: 626-634.

45. Peelle JE, Troiani V, Grossman M, Wingfield A. Hearing loss in older adults affects neural systems supporting speech comprehension. J Neurosci. 2011;31:12638-12643.

46. Classon E, Löfkvist U, Rudner M, Rönnberg J. Verbal fluency in adults with postlingually acquired hearing impairment. Speech, Language and Hearing. 2014;17:88-100.

47. Zekveld AA, Deijen JB, Goverts ST, Kramer SE. The relationship between nonverbal cognitive functions and hearing loss. J Speech Lang Hear Res. 2007;50:74-82.

48. van Boxtel MP, van Beijsterveldt CE, Houx PJ, Anteunis LJ, Metsemakers JF, Jolles J. Mild hearing impairment can reduce verbal memory performance in a healthy adult population. $J$ Clin Exp Neuropsychol. 2000;22:147-154.
Clinical Interventions in Aging

\section{Publish your work in this journal}

Clinical Interventions in Aging is an international, peer-reviewed journal focusing on evidence-based reports on the value or lack thereof of treatments intended to prevent or delay the onset of maladaptive correlates of aging in human beings. This journal is indexed on PubMed Central, MedLine,

\section{Dovepress}

CAS, Scopus and the Elsevier Bibliographic databases. The manuscript management system is completely online and includes a very quick and fair peer-review system, which is all easy to use. Visit http://www.dovepress. com/testimonials.php to read real quotes from published authors. 